\title{
Inhibition of demand pacemakers caused by potentials associated with inspiration
}

\author{
Thomas Peter, Richard Harper, and Graeme Sloman \\ From the Cardiac Laboratory, Royal Melbourne Hospital, Victoria, Australia
}

A 69-year-old man with a permanent demand pacemaker and a unipolar electrode system had intermittent failure of pacing during deep inspiration. Pacing was not interrupted when the unit was switched to fixed rate mode by an external magnet. Thus, the problem was not caused by a change in electrode position or to a loose connexion. The likely cause was inhibition by non-cardiac potentials, possibly myopotentials associated with respiration.

Since the advent of demand systems in cardiac pacemakers, interference by external electromagnetic field has been well recognized (Furman et al., 1968; Bilitch, Lau, and Cosby, 1967). Recently it has been reported that inhibition can also be provoked by myopotentials emanating from muscles surrounding the pacemaker (Piller and Kennelly, 1974; Gribbin, Abson, and Clarke, 1974; Ohm et al., 1974). The purpose of this paper is to report inhibition of demand pacing caused by muscle potentials associated with deep inspiration in a patient.

\section{Case report}

A 69-year-old man presented to the Royal Melbourne Hospital in May 1973, with a history of recurrent syncopal episodes over the preceding 12 months. A demand pacemaker (Telectronic Pro) set at a rate of $90 / \mathrm{min}$ was implanted with a unipolar endocardial electrode and the patient was followed regularly at the Pacemaker Clinic (Mond et al., 1972). In October 1974, the characteristics of the pacemaker potential showed no change from those recorded 6 months earlier. However, a fault which was detected during one routine test is illustrated in the Fig. The pause following $\mathrm{R}_{5}$ is recorded during deep inspiration, and is terminated by an escape complex. Electronic analysis revealed that tracking potentials were emitted from the pacemaker during the pause: this model of pacemaker is designed to give small nonstimulating pulses synchronous with inhibiting complexes to indicate normal demand function during spontaneous rhythm. The patient remained asymptomatic during these brief periods when pacing was inhibited. The phenomenon was repeatedly observed and recorded during two further visits to the pacemaker clinic and each time this could be easily provoked by deep inspiration. The Fig. (B) shows regular pacing continuing even during deep inspiration after application of the magnet to switch the unit to a fixed rate mode.

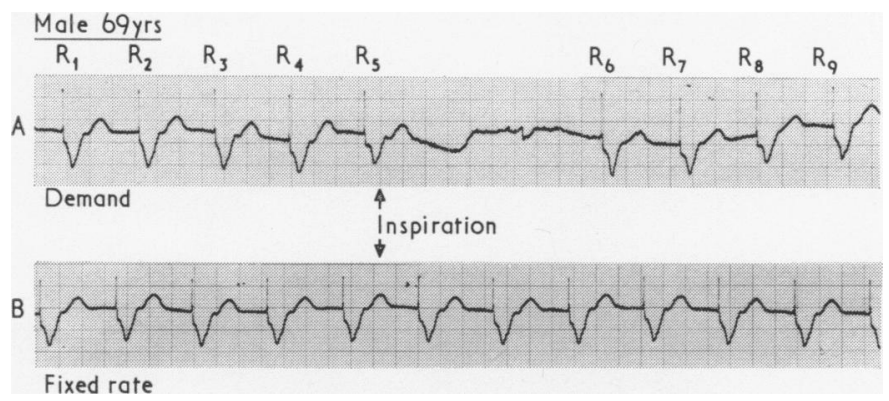

FIG. (A) Demand pacing rhythm, lead II; (B) Fixed rate pacing rhythm, lead II. Arrows indicate the onset of deep inspiration in both $A$ and $B$. 


\section{Discussion}

Skeletal muscle potentials were first reported to cause inhibition of unipolar demand pacemakers by Wirtzfeld, Lampadius, and Ruprecht in 1972. Such interference has been reported in up to 50 per cent of patients with unipolar pacemakers during either isometric contraction of pectoralis major or arm movements (Wirtzfeld, Lampadius, and Schmuck, 1973; Mymin et al., 1973; Barold, 1974). Similar inhibition by non-cardiac body potentials has not been reported previously in association with deep inspiration. Presumably this phenomenon in our patient was caused by potentials emanating from the respiratory muscles.

The fault was not caused by wire fracture or by a loose connexion, because pacing was maintained during deep inspiration when the system was switched to fixed-rate mode.

\section{References}

Barold, S. S. (1974). Current problems with demand pacemakers. European fournal of Cardiology, 1, 339.

Bilitch, M., Lau, F. Y. K., and Cosby, R. S. (I967). Demand pacemaker inhibition by radio-frequency signals (abstract). Circulation : 36 : Suppl. II : 68 .
Furman, S., Parker, B., Krauuamer, M., and Esher, D. J. W. (1968). The influence of electromagnetic environment on the performance of artificial cardiac pacemakers. Annals of Thoracic Surgery, 6, 90.

Gribbin, B., Abson, C. P., and Clarke, L. M. (1974). Inhibition of external demand pacemakers during muscular activity. British Heart fournal, 36, 1210.

Mond, H., Twentyman, R., Smith, D., and Sloman, G. (1972). The pacemaker clinic. Cardiology, 57, 262.

Mymin, D., Cuddy, T. E., Sinha, S. N., and Winter, D. A. (1973). Inhibition of demand pacemakers by skeletal muscle potentials. Fournal of the American Medical Association, $223,527$.

Ohm, O.-J., Bruland, H., Pedersen, O. M., and Waerness, E. (1974). Interference effect of myopotentials on function of unipolar demand pacemakers. British Heart fournal, 36, 77.

Piller, L. W., and Kennelly, B. M. (1974). Myopotential inhibition of demand pacemakers. Chest, 66, 418.

Wirtzfeld, A., Lampadius, M., and Ruprecht, E. O. (1972). Unterdrückung von Demand-Schrittmachern durch Muskelpotentiale. Deutsche medizinische Wochenschrift, 97, 6r.

Wirtzfeld; A., Lampadius, M., Schmuck, L. (1973). The influence of muscle potentials on synchronous pacemakers. In Cardiac Pacing: Proceedings of the 4th International Symposium, p. 169. Ed. by H. J. Thalen. Van Gorcum, Assen, Netherlands.

Requests for reprints to Dr. Graeme Sloman, Cardiac Laboratory, Royal Melbourne Hospital, Victoria, Australia 3050. 